\title{
Moral, direitos humanos e participação social ${ }^{\mathbf{1}}$
}

\author{
Cleonice Camino \\ Universidade Federal da Paraíba \\ Universidade Federal de Pernambuco \\ Leoncio Camino \\ Universidade Federal da Paraíba \\ Cícero Pereira \\ Universidade Católica de Goiás \\ Márcia Paz \\ Universidade Federal da Paraíba
}

\begin{abstract}
Resumo
Este artigo verifica a representação que universitários têm do seu envolvimento e do envolvimento do governo com os Direitos Humanos (DH), analisa a relação entre essa representação e variáveis psicossociais e compara alguns valores morais veiculados pela Rede Globo de Televisão à representação dos universitários. Para verificar as representações dos estudantes sobre os $\mathrm{DH}$, foi realizado, baseado na teoria psicossociológica das representações sociais, um estudo com 93 universitários da UFPB e da UEPB. Os resultados revelaram que a representação do envolvimento possui quatro dimensões - pessoal-abstrato, pessoal-concreto, governamental-abstrato e governamental-concreto; o compromisso dos estudantes é maior com direitos individuais do que com direitos societais; a representação do envolvimento com os DH está ancorada, sobretudo, na identificação partidária e na participação desses estudantes em atividades sócio-políticas; e que existe uma similitude entre valores morais predominantes nos programas analisados e o tipo de artigo da Declaração Universal dos Direitos Humanos mais valorizado pelos estudantes.
\end{abstract}

Palavras-chave: moral; direitos humanos; participação social

\begin{abstract}
Morality, human rights and social participation. This article analyzes the representation university students make of their own involvement and the involvement of the government with Human Rights (HR); it also analyzes the relationship between this representation and the psychosocial variables and compares some moral values transmitted by Rede Globo de Televisão (the most influential TV channel in Brazil) to the university students' representation. A study based on the psychosocial theory of the social representations was carried out with 93 university students from UFPB and UEPB in order to check the students' representation about HR. The results revealed that the representation of the involvement has four dimensions - the abstract-personal, the concrete-personal, the abstract-governmental and the concrete-governmental. It was found that the students' commitment with individual rights is stronger than with societal rights; the representation of the involvement with HR is mainly grounded on party affiliations and on the participation of these students in socio-political activities. There is also a similarity between the prevailing moral values of the TV programs under examination and the type of article of the Universal Declaration of Human Rights the students support more strongly.
\end{abstract}

Key-words: morality; human rights; social participation

$\mathrm{N}$ as últimas décadas, no Brasil, no bojo do processo de democratização, tem-se constatado um alto grau de corrupção subjacente à elite dominante. Se, no início, reagiu-se com indignação, levando-se o presidente Collor ao impeachment, atualmente, assiste-se com uma certa resignação ao contínuo surgimento de novos escândalos em todos os níveis da administração pública e privada. Como corolário desta situação, tem-se a moral como um tema em evidência em várias áreas de estudo.

Tradicionalmente, a Psicologia tem-se limitado ao estudo do equilíbrio psicológico e moral dos indivíduos. Mas a situação atual exige dela, em colaboração com outras ciênci- 
as, como a Filosofia, a Sociologia, as Ciências Políticas, etc., um olhar para o estudo da moral pública. Neste sentido, algumas perguntas fundamentais deverão ser respondidas: quais são os direitos que as pessoas julgam ser importantes para manter o equilíbrio social, qual, entre os diversos agentes sociais, deve ser o responsável pela execução desses direitos, e de que forma?

Para melhor compreender como as pessoas se posicionam frente aos direitos humanos, é importante considerar o fato de que normas e princípios morais (valores) regulam uma sociedade (moral coletiva), e que, por isso, todo aquele inserido em uma determinada sociedade deverá, de algum modo, aprender a viver sob essas normas e princípios. Esta relação entre o indivíduo e a sociedade justifica, portanto, uma explanação sobre a forma pela qual o sujeito desenvolve-se moralmente (moral individual).

Vários teóricos da Psicologia têm procurado compreender como ocorre o desenvolvimento moral individual, dentre eles, destacam-se, neste trabalho, Jean Piaget e Lawrence Kohlberg. Esses autores, em seus estudos, distinguiram dois grandes tipos de moral: a moral heterônoma - em que os indivíduos simplesmente apropriam-se dos valores e regulamentações sociais existentes; e a moral autônoma - em que os indivíduos participam como co-autores na elaboração das normas e valores coletivos e, neste processo, constróem seus próprios valores e adquirem respeito pelas normas ${ }^{2}$.

Apesar de teoricamente esses autores abordarem a formação de uma moral coletiva, poucos seguidores têm-se debruçado sobre o estudo das morais coletivas e sobre a relação destas com a moral individual. E é com esta preocupação que autores como Camino e Cavalcanti (1998) e Dâmaso (1995) têm estudado os valores morais transmitidos pela mídia televisiva brasileira, tendo como suporte o enfoque teórico de Kohlberg $(1976,1984)$ e entendendo que, através das imagens e narrativas veiculadas pela mídia, é possível fazer uma leitura dos valores e das crenças existentes na sociedade (Kelner, 2001).

A escolha da TV explica-se pelo fato de que as crianças e adolescentes brasileiros apresentam uma média nacional elevada de exposição à TV - 4 horas diárias - (Projeto Kids, 1996, citado por Sampaio, 2000). Dentro da mídia televisiva, foram investigados o programa Você Decide (Dâmaso, 1995) e telenovelas (Camino \& Cavalcanti, 1998), por constituírem programas com elevada audiência formada por telespectadores de todas as classes sociais e de todas as faixas etárias (Mello, 1988; Sampaio, 2000).

As telenovelas analisadas por Camino e Cavalcanti (1998) - Vale Tudo, Salvador da Pátria e Tieta - foram transmitidas consecutivamente pela Rede Globo entre os anos de 1988 e 1990, sempre no horário das 20h30m. Nos resultados obtidos, os autores verificaram a predominância de dois tipos de moral: uma voltada para os interesses individuais moral da individualidade - e outra baseada nas convenções sociais grupais - moral corporativista -, que correspondem em grande parte, respectivamente, às morais dos estágios 2 e 3 da tipologia kohlberguiana (Kohlberg, 1976, 1984).
A moral da individualidade caracteriza-se por valores utilitaristas e hedonistas, por uma justiça punitiva de tipo expiatória e por uma ausência de responsabilidade frente às faltas cometidas. Já a moral corporativista caracteriza-se pela preocupação referente ao bem-estar do outro, pelo cuidado com o manter as amizades e pela preocupação em ser bem visto pelos outros. Nesta moral, valores como a cooperação, a solidariedade, a fidelidade e a ajuda estão presentes. Os valores desta moral, às vezes, apresentam-se em conflito com valores relativos ao bem-estar da coletividade. Nestes casos, normalmente, são os valores corporativistas que prevalecem.

Deve-se notar que, nas telenovelas analisadas, não são praticamente apresentados valores ou normas morais referentes à legalidade. Assim, constata-se que nas telenovelas a ordem social e a manutenção dos direitos humanos não constituem objeto de discussão. A discussão de situações de interesse social e a discussão de problemas como violência, miséria e corrupção também não são realizadas. Os problemas sociais são sempre reduzidos à escala do individual ou interindividual.

Em relação ao programa Você Decide, Dâmaso (1995) analisou cinco episódios: "Direito de Morrer", "O Porteiro", “Chofer de Táxi”, “Abuso Sexual” e “Achados e Perdidos”. Os resultados dessa análise indicaram que os personagens apresentavam, sobretudo, valores morais relativos ao benefício pessoal, à obtenção do prazer individualista, ao benefício do outro desde que isso resultasse em aceitação social e à busca de relações satisfatórias. Segundo Dâmaso (1995), nos conteúdos morais apresentados, foram poucos os que se relacionaram ao bem comum em um nível social mais amplo.

Observam-se, nos resultados das duas pesquisas, valores semelhantes veiculados pela TV em programas diferentes. A partir desses resultados, cabe perguntar se existe correspondência entre os valores morais televisivos e os valores morais individuais, e, se existe, por que ocorre essa correspondência. Segundo os autores deste trabalho, o enfoque cognitivo-construtivista não responde bem a esta questão, uma vez que privilegia mais em seu modelo teórico e estudos empíricos a influência da moral de grupo na moral individual ou a reconstrução dos valores sociais feita pelo próprio indivíduo do que a influência de valores societais na moral individual.

Frente a estas considerações, julgou-se que seria necessária uma abordagem que pudesse analisar a relação entre moral individual e moral societal diferente do cognitivismo construtivista, uma abordagem que permitisse investigar a influência de fatores sociais amplos na formação sócio-moral do indivíduo.

Uma posição teórica que parece responder melhor às perguntas apresentadas e preencher, portanto, as lacunas deixadas pelo cognitivismo construtivista é a articulação psicossociológica proposta por Doise (1976), posto que este autor procura fazer uma integração entre aspectos individuais, interindividuais, intergrupais e sociais. De fato, para Doise (1982), o desenvolvimento psicológico do indivíduo é em parte decorrente do processo de internalização de normas e valo- 
res, e em parte, decorrente de uma auto-reflexão. Assim, uma das formas de analisar a influência que as morais coletivas têm na percepção que os indivíduos constróem dos seus direitos e de seus deveres pode ser através de pesquisas realizadas sobre os direitos humanos, a partir de um enfoque psicossociológico.

Antes de entrar nos estudos de Doise (1998), parece importante descrever como as pessoas representam o conjunto de direitos que constituem a Declaração Universal dos Direitos Humanos (DUDH). Diaz-Veizades, Widaman, Little e Gibbs (1995) mostraram que a atitude de norte-americanos em relação ao conjunto de direitos organiza-se em quatro tópicos: direitos econômicos; direitos civis e políticos; direitos e igualdades sem discriminação de gênero, raça e crenças; e direitos à vida privada. Como era de se esperar, Doise e colaboradores (Clémence, Doise, De Rosa, \& Gonzalez, 1995; Doise, Spini, \& Clémence, 1999) têm constatado que essa organização mostra um certo grau de variação entre diferentes países.

Seja qual for a forma como os direitos humanos são vistos em cada cultura, fica ainda a questão de saber como as pessoas representam seus compromissos com esses direitos. Em uma pesquisa transcultural realizada em $35^{3}$ países com uma amostra de 6.791 estudantes, Doise, Spini e Clémence (1999) avaliaram, em relação a 30 artigos da DUDH, tanto a importância atribuída pelos respondentes a esses artigos, quanto sua compreensão.

Os resultados indicaram que os escores médios dos países diferenciavam-se em relação a quatro funções discriminantes: a primeira opunha uma adesão passiva aos direitos a uma adesão ativa; a segunda opunha uma posição personalista aos direitos a uma posição governamentalista; a terceira referia-se à eficácia da participação política e a quarta à ação governamentalista. Nessa análise, os escores da amostra brasileira, como também os das amostras de Indonésia, Filipinas, Tunísia, Costa do Marfim, Camarões e Zaire, foram altos em relação à posição personalista da segunda função e baixos em relação à posição que indica a ação governamental - da quarta função.

Doise e Herrera (1994), em pesquisa realizada sobre os $\mathrm{DH}$, pediram a moradores da cidade de Genebra que enumerassem os $\mathrm{DH}$ que eles conheciam. Nos resultados, verificaram que entre os direitos mais citados estavam os princípios fundamentais (Artigos $1^{\underline{0}}$ e $2^{\underline{0}}$ ) e, dentre os menos citados, encontravam-se os relacionados com a ordem social e as relações internacionais (Artigos 28 a 30). Com base nesses resultados, os autores concluíram que, após 50 anos da proclamação da DUDH, as pessoas privilegiam os artigos que tratam dos direitos individuais e fundamentais, apresentando assim, uma imagem dos DH baseada na visão jurídica puramente formal. Em uma segunda fase desta pesquisa, os autores administraram um questionário contendo os 30 artigos proclamados pela DUDH e solicitaram dos sujeitos que indicassem o quanto eles e o governo contribuíam para o cumprimento dos DH. Nos resultados, os autores observaram que, com relação às contribuições pessoais, os sujeitos conside- raram que contribuíam mais para os direitos referentes à esfera individual (Artigos $1^{\underline{0}}$ e $2^{\underline{0}}$ ) do que para os referentes às esferas social e internacional. Com relação ao governo, consideraram que ele contribuía menos para o cumprimento dos princípios fundamentais do que para os $\mathrm{DH}$ referentes às relações interpessoais (Artigos 12 a 17).

Em uma outra pesquisa, Spini e Doise (1998) realizaram um estudo no qual identificaram os princípios organizadores da representação de estudantes universitários de Genebra sobre o envolvimento destes com os direitos humanos. Os resultados mostraram que as representações que os estudantes tinham da responsabilidade no cumprimento dos direitos humanos distribuíam-se em duas dimensões bipolares: governamental-pessoal, dependendo da pessoa a quem se atribuía a responsabilidade; e abstrato-concreto dependendo do nível de compromisso. A combinação dessas duas dimensões bipolares constituíram quatro princípios organizadores: pessoal-abstrato, pessoal-concreto, governamental-abstrato e governamental concreto.

Conforme Spini e Doise (1998), quando se considera a dimensão governamental versus pessoal, verifica-se que o princípio governamental está relacionado com a crença tradicionalmente compartilhada de que a aplicação dos direitos humanos deveria ser feita pelos países membros da Organização das Nações Unidas. Realmente, o preâmbulo da DUDH - Declaração Universal dos Direitos Humanos, publicada em 1948, atribui aos governos a responsabilidade no cumprimento desses direitos, ao considerar que os Estados Membros se comprometeram a promover, em cooperação com as Nações Unidas, o respeito universal aos direitos e liberdades fundamentais do homem e a observância desses direitos e liberdades. Essa crença comum pode ser vista como uma influência ideológica da DUDH.

A interpretação de Spini e Doise (1998) para a presença de um princípio pessoal no cumprimento dos direitos humanos é a de que a participação de indivíduos na luta pela promoção dos direitos influencia a percepção das pessoas no que concerne ao envolvimento individual. Uma outra explicação para a presença desse princípio é a de que foi afirmada formalmente a necessidade da participação individual na aplicação dos direitos humanos, na Conferência Internacional das Nações Unidas sobre os Direitos Humanos, realizada em Viena, em 1993 (United Nations, 1993).

Quanto à dimensão de envolvimento abstrato versus concreto, segundo Spini e Doise (1998), ela se refere à distinção dos indivíduos entre o que eles poderiam ou deveriam fazer e o que eles efetivamente fazem quando respondem a questões de interesse social. Esses indivíduos tendem a atribuir alto grau de concordância nas respostas desejáveis socialmente, enquanto que nas questões referentes a ações concretas, freqüentemente atribuem sua real posição.

Uma investigação aprofundada dessa dimensão foi desenvolvida por Doise, Dell’Ambrogio e Spini (1991) numa pesquisa na qual os sujeitos expressaram suas opiniões sobre vários casos julgados pela Corte Européia dos Direitos Humanos. Nesse estudo, todos os indivíduos apresentaram 
um elevado grau de adesão aos direitos humanos, quando esses foram discutidos no nível abstrato e geral. Porém, as diferenças individuais surgiram quando foram julgados dilemas concretos. Assim, enquanto havia um consenso de todos os indivíduos na condenação da prática da tortura por policiais em termos abstratos, o consenso desapareceu quando a pessoa torturada era um suposto terrorista que possuía informações sobre um possível atentado contra a população civil.

Spini e Doise (1998) ainda relatam uma pesquisa realizada por Moghaddam e Vuksanovic (1990, citado por Spini \& Doise, 1998) na qual pediram a estudantes canadenses que indicassem o seu grau de concordância a 21 itens que descreviam os DH contextualizados em três tipos diferentes de países: Canadá, União Soviética e países do terceiro mundo. Os resultados indicaram que, nos diferentes contextos, a adesão aos DH se correlacionou negativamente com a identificação dos estudantes com partidos políticos de direita e com o autoritarismo.

Em um outro estudo, realizado com 76 jovens suíços alunos do ensino médio, Staerklé, Clémence e Doise (1998) verificaram se a atribuição de responsabilidade pelo cumprimento dos $\mathrm{DH}$, em um determinado país, tinha a ver com o tipo de governo e o tipo de população. Para tanto, administraram aos estudantes, divididos em quatro grupos diferentes, questionários que continham um pequeno texto sobre um suposto governo, ou uma suposta população. O governo era descrito ou de forma democrática ou de forma autoritária, e a população era descrita ou como Debatedora ou como Conflituosa. Os resultados indicaram que na condição país democrata com população debatedora o grau de atribuição de respeito e de exercício dos direitos foi superior ao da condição país autoritário com relações conflituosas. Segundo os autores, estes resultados mostraram que os sujeitos acreditavam que era mais difícil exercer ações garantidas pela DUDH nas outras condições experimentais.

A partir dos resultados dessas pesquisas, pode-se indagar: (1) como estudantes universitários da Paraíba consideram a responsabilidade do governo e a sua em relação aos DH? e (2) qual a relação entre a percepção de responsabilidade perante os $\mathrm{DH}$ e a participação social dos sujeitos? Por outro lado, considerando os tipos de moral disseminados na sociedade brasileira - moral individualista e moral corporativista - pergunta-se: é possível estabelecer uma correspondência entre essas morais e o nível de compromisso dos estudantes com os $\mathrm{DH}$ quando se trata de direitos relativos ao indivíduo e ao bem estar do outro e da comunidade? Com o objetivo de responder às duas primeiras indagações foi realizada uma investigação empírica sobre as representações que estudantes de Psicologia têm do seu envolvimento e do envolvimento do governo com respeito aos direitos humanos e sobre a inserção social desses estudantes. Para responder à terceira questão foi feita uma comparação entre os resultados obtidos nesta pesquisa e os resultados obtidos nas pesquisas sobre os valores morais transmitidos pelos meios de comunicação em massa.
Método

\section{Participantes}

Participaram desta investigação 93 estudantes de ambos os sexos, do curso de Psicologia das Universidades Federal e Estadual da Paraíba. A idade média dos estudantes foi de 20,6 anos (dp = 4,61).

\section{Instrumento}

Os estudantes responderam a um questionário desenvolvido por Spini e Doise (1998) que, além de avaliar as características sócio-demográficas dos estudantes (idade, sexo e tempo de universidade), analisa as representações que os universitários têm do envolvimento nos direitos humanos e a sua participação social. Com relação aos direitos humanos, são analisadas apenas representações concernentes aos Artigos $1^{0}$ e 29 da DUDH. O Artigo $1^{0}$ proclama o direito fundamental à liberdade e à igualdade entre os homens: "Todos os homens nascem livres e iguais em dignidade e em direitos. São dotados de razão e consciência e devem agir em relação uns aos outros com espírito de fraternidade”. O Artigo 29 descreve o dever de todos de respeitar os direitos dos outros: I. Todo homem tem deveres para com a comunidade, na qual o livre e pleno desenvolvimento de sua personalidade é possível. II. No exercício de seus direitos e liberdades, todo homem estará sujeito apenas às limitações determinadas pela lei, exclusivamente com o fim de assegurar o devido reconhecimento e respeito dos direitos e liberdades de outrem e de satisfazer às justas exigências da moral, da ordem pública e do bem-estar de uma sociedade democrática. III. Esses direitos e liberdades não podem, em hipótese alguma, ser exercidos contrariamente aos objetivos e princípios das Nações Unidas.

Cada direito foi seguido por oito pares de sentenças. Cada par foi constituído por uma sentença positiva e outra negativa, para as quais os estudantes indicaram seu grau de adesão numa escala bipolar de nove pontos, que variava de 4 (menor envolvimento) a +4 (envolvimento mais elevado). Para cada um dos princípios organizadores do envolvimento nos direitos humanos foram apresentados dois pares de sentenças. Assim, para o envolvimento Pessoal-Abstrato foram utilizados os pares de sentenças: "Eu devo (eu não devo) fazer muito para a aplicação desses direitos” e "Eu posso (eu não posso) fazer muito para a aplicação desses direitos”. Para o envolvimento Pessoal-Concreto foram apresentados os pares de sentenças: "Eu me empenho (não me empenho) suficientemente na aplicação desses direitos” e “Eu invisto (não invisto) de uma maneira concreta para fazer aplicar esses direitos”. A percepção de envolvimento Governamental-Abstrato foi avaliada através das sentenças: “O governo brasileiro deve (não deve) fazer muito para aplicação desses direitos” e "O governo brasileiro pode (não pode) fazer muito para a aplicação desses direitos”. Finalmente, para a análise da percepção do envolvimento Governamental-Concreto foram utilizadas as sentenças: "O governo brasileiro investe (não investe) de uma maneira concreta para fazer aplicar es- 
ses direitos" e "O governo brasileiro empenha-se (não se empenha) suficientemente na aplicação desses direitos”.

Com relação à participação social dos estudantes, apresentou-se uma lista contendo cinco formas de participação sócio-política na qual os estudantes indicaram a sua participação ou a não-participação em cada uma das atividades da lista: abaixo-assinados de protesto; votar, mesmo se não fosse obrigatório; participar de manifestações em defesa dos direitos humanos; pertencer a comitês de defesa dos direitos humanos; ser membro de uma organização não-governamental. Em seguida, solicitou-se aos estudantes que indicassem o partido político de sua simpatia. O levantamento dos partidos mencionados permitiu classificar a identificação partidária em esquerda e direita conforme os resultados das pesquisas desenvolvidas na Paraíba sobre a representação da estrutura partidária em estudantes universitários (Camino, Torres \& Da Costa, 1995; Mendoza \& Camino, 2000) e no eleitorado em geral (Camino, Silva \& Souza, 1998).

\section{Procedimentos}

Os questionários foram aplicados em salas de aulas definidas através de sorteios. Para a realização dos sorteios, foram solicitadas da coordenação do curso as grades curriculares contendo o nome das disciplinas e seus respectivos horários e números de sala. Após os sorteios, solicitouse aos professores de cada disciplina a autorização para a realização da coleta dos dados. Todos os alunos prontificaramse a responder os questionários, utilizando 20 a 30 minutos para a execução da tarefa.

\section{Resultados}

Para avaliar a estrutura dos princípios que organizam a percepção dos estudantes sobre o envolvimento no cumprimento dos direitos, foi aplicada uma Análise dos Componentes Principais para cada um dos dois direitos, fixando-se a priori o limite de quatro fatores. Os resultados indicam que os quatro princípios organizadores descritos por Spini e Doise (1998) foram utilizados pelos participantes, todos com eigenvalue superiores a 1 , explicando $81 \%$ da variabilidade total no direito relativo ao Artigo $1^{\circ}$ e $82 \%$, no direito proclamado no Artigo 29 (Tabela 1).

Analisou-se posteriormente o posicionamento dos estudantes através de combinações entre os direitos e os quatro princípios. Os resultados da Análise de Variância (Tabela 2) indicam que todos os efeitos principais são significativos. Como esperado, a percepção de envolvimento no conteúdo do Artigo $1^{0}$ (média $=1,5$ ) é maior do que com o relativo ao Artigo 29 (média =1,2), $F_{(1,90)}=4,382 ; p<0,05$. Observou-se também que a percepção do envolvimento pessoal (média = 1,9) é superior à percepção do envolvimento do governo brasileiro (média $=0,79 ; F_{(1,90)}=52,421 ; p<0,001$ ), e que o nível

Tabela 1

Resultados da análise dos componentes principais da percepção dos estudantes sobre o envolvimento no cumprimento dos Artigos $1^{0}$ e 29 da DUDH

\begin{tabular}{|c|c|c|c|c|c|c|c|c|c|c|}
\hline \multirow[b]{4}{*}{ Itens Abreviados } & \multicolumn{8}{|c|}{ Princípios Organizadores } & \multirow{2}{*}{\multicolumn{2}{|c|}{$h^{2}$}} \\
\hline & \multicolumn{2}{|c|}{$\begin{array}{l}\text { Pessoal } \\
\text { Concreto }\end{array}$} & \multicolumn{2}{|c|}{$\begin{array}{l}\text { Governo } \\
\text { Concreto }\end{array}$} & \multicolumn{2}{|c|}{$\begin{array}{l}\text { Pessoal } \\
\text { Abstrato }\end{array}$} & \multicolumn{2}{|c|}{$\begin{array}{l}\text { Governo } \\
\text { Abstrato }\end{array}$} & & \\
\hline & & & & & & & & & & \\
\hline & $1^{o}$ & 29 & $1^{\mathrm{o}}$ & 29 & $1^{o}$ & 29 & $1^{\underline{o}}$ & 29 & $1^{\underline{o}}$ & 29 \\
\hline $\begin{array}{l}\text { Eu me empenho } \\
\text { suficientemente... }\end{array}$ & 0,92 & 0,92 & & & & & & & 0,86 & 0,85 \\
\hline $\begin{array}{l}\text { Eu invisto de maneira } \\
\text { concreta... }\end{array}$ & 0,90 & 0,90 & & & & & & & 0,85 & 0,84 \\
\hline $\begin{array}{l}\text { O governo brasileiro } \\
\text { empenha-se... }\end{array}$ & & & 0,90 & 0,91 & & & & & 0,82 & 0,84 \\
\hline $\begin{array}{l}\text { O governo brasileiro } \\
\text { investe... }\end{array}$ & & & 0,88 & 0,87 & & & & & 0,81 & 0,84 \\
\hline $\begin{array}{l}\text { Eu posso fazer muito } \\
\text { para... }\end{array}$ & & & & & 0,88 & 0,91 & & & 0,81 & 0,82 \\
\hline $\begin{array}{l}\text { Eu tenho parte de } \\
\text { responsabilidade... }\end{array}$ & & & & & 0,87 & 0,86 & & & 0,79 & 0,78 \\
\hline $\begin{array}{l}\text { O governo tem parte } \\
\text { de responsabilidade... }\end{array}$ & & & & & & & 0,84 & 0,93 & 0,72 & 0,88 \\
\hline $\begin{array}{l}\text { O governo brasileiro } \\
\text { pode fazer muito... }\end{array}$ & & & & & & & 0,84 & 0,64 & 0,72 & 0,68 \\
\hline Eigenvalue & 1,66 & 1,66 & 1,58 & 1,59 & 1,53 & 1,57 & 1,41 & 1,27 & & \\
\hline Variância explicada & $28 \%$ & $32 \%$ & $23 \%$ & $20 \%$ & $16 \%$ & $19 \%$ & $14 \%$ & $11 \%$ & & \\
\hline
\end{tabular}


Tabela 2

Médias da percepção dos estudantes sobre envolvimento nos direitos humanos em função do tipo de direito, do tipo e do nível de envolviment.

\begin{tabular}{llccc}
\hline & & \multicolumn{2}{c}{ Nível de Envolvimento } \\
\hline Tipo de Direito & Tipo de Envolvimento & Envolvimento Abstrato & $\begin{array}{c}\text { Envolvimento } \\
\text { Concreto }\end{array}$ & Total \\
\hline Artigo 1 & Pessoal & $3,3_{\mathrm{a}}$ & $1,7_{\mathrm{c}}$ & $2,5_{\mathrm{a}}$ \\
& Governamental & $3,0_{\mathrm{a}}$ & $-2,0_{\mathrm{f}}$ & $0,5_{\mathrm{d}}$ \\
Artigo 29 & Pessoal & $2,3_{\mathrm{b}}$ & $0,5_{\mathrm{d}}$ & $1,4_{\mathrm{b}}$ \\
& Governamental & $3,0_{\mathrm{a}}$ & $-0,8_{\mathrm{c}}$ & $1,1_{\mathrm{c}}$ \\
\hline & Total & $2,9_{\mathrm{a}}$ & $-0,2_{\mathrm{b}}$ & 1,4 \\
\hline
\end{tabular}

Nota: As médias que não compartilham o mesmo subscrito representam diferenças significativas no teste de Duncan, com $p<0,05$. A escala varia de -4 (menor envolvimento) a +4 (envolvimento mais elevado).

de envolvimento abstrato (média $=2,9$ ) é bem maior do que o concreto (média = - 0,2), $F_{(1,90)}=339,77 ; p<0,001$.

Além disso, a percepção de envolvimento pessoal dos estudantes em relação ao Artigo $1^{\underline{0}}$ (média = 2,5) é superior ao que possuem em relação ao Artigo 29 (média = 1,4). Já a percepção do envolvimento do governo brasileiro com o conteúdo do Artigo 29 (média = 1,1) é maior do que o envolvimento com o Artigo $1^{0}$ (média $=0,5$ ). No nível abstrato, os estudantes consideram que eles têm menos responsabilidade no cumprimento do Artigo 29 (média = 2,3) do que no cumprimento do Artigo $1^{0}$ (média $=3,3$ ). No nível concreto, eles percebem que estão pessoalmente mais envolvidos na aplicação do conteúdo referente ao Artigo $1^{\underline{0}}$ (média $=1,7$ ) do que no referente ao Artigo 29 (média $=0,5$ ). Já o governo brasileiro é apontado como menos envolvido com o comprimento do primeiro Artigo (média = -2,0) do que com o vigésimo nono (média $=-0,8)$.

Foi analisada também a influência de fatores psicossociais no nível de envolvimento dos indivíduos e na percepção deles em relação ao envolvimento do governo brasileiro (Tabela 3). Neste sentido, efetuou-se um conjunto de regressões múltiplas, utilizando-se como variáveis dependentes os quatro princípios organizadores e, como variáveis independentes, as características sócio-demográficas dos estudantes (idade, sexo, tempo de universidade), a sua simpatia partidária e a sua participação num conjunto de atividades sócio-políticas.

Com relação ao direito de igualdade/liberdade - Artigo $1^{\underline{0}}$, os estudantes que simpatizam com partidos políticos de esquerda são os que apresentam um maior envolvimento pessoal no nível abstrato - no que deveria ser. Já os com maior tempo de universidade e os que têm simpatia por partidos de direita são os que estão menos concretamente envolvidos na aplicação deste direito. Por outro lado, os simpatizantes de direita percebem que o governo brasileiro investe de uma maneira concreta na aplicação deste direito, enquanto que os estudantes mais velhos, os que votariam mesmo que o voto não fosse obrigatório e os que participam de ma- nifestações, são os que apresentam uma visão mais crítica no que se refere ao envolvimento do governo.

No que concerne ao direito referente ao bem-estar social - Artigo 29, os resultados demonstram que os estudantes membros de alguma organização que se ocupa com a promoção dos direitos humanos são os que apresentam um nível mais elevado de envolvimento pessoal abstrato, enquanto aqueles com um maior tempo de universidade são os menos envolvidos. Os simpatizantes por partidos políticos de direita e os que participam de manifestações consideram que estão concretamente menos envolvidos na aplicação deste direito. Os estudantes que participam de manifestações são, também, os que têm uma visão mais crítica do empenho do governo brasileiro na aplicação desse direito. É importante destacar que, nos dois direitos relativos aos Artigos $1^{0}$ e 29 , a percepção do envolvimento do governo brasileiro ao nível abstrato não apresentou nenhuma relação com a participação psicossocial dos estudantes.

\section{Discussão}

Procurou-se neste trabalho investigar tanto a representação de estudantes de psicologia da Paraíba sobre o envolvimento pessoal e o envolvimento atribuído ao governo brasileiro a respeito de direitos humanos, como a relação dessa representação com a participação social dos estudantes e com a moral veiculada por telenovelas brasileiras e o programa Você Decide.

Os resultados mostram que os direitos humanos agrupam-se em 4 princípios organizativos: pessoal-abstrato, pessoal-concreto, governamental-concreto e governamental-abstrato, e apóiam os resultados encontrados por Spini e Doise (1998) e por Doise, Staerklé, Clémence e Savory (1998). Os envolvimentos pessoal e governamental dos estudantes em termos abstratos - tanto em relação ao Artigo $1^{\underline{0}}$, que proclama o direto fundamental ("todos os homens nascem livres e iguais em dignidade e em direitos”), como em relação ao Artigo 29, que aponta para o dever de todos para com a comuni- 
Tabela 3

Conjunto de regressões múltiplas utilizadas na análise da ancoragem dos princípios organizadores do envolvimento no cumprimento dos Artigos $1^{0}$ e 29 da DUDH

\begin{tabular}{|c|c|c|c|c|c|c|c|c|}
\hline \multirow{4}{*}{ Variáveis Antecedentes } & \multicolumn{8}{|c|}{ Princípios Organizadores } \\
\hline & \multicolumn{2}{|c|}{$\begin{array}{l}\text { Pessoal } \\
\text { Abstrato }\end{array}$} & \multicolumn{2}{|c|}{$\begin{array}{l}\text { Pessoal } \\
\text { Concreto }\end{array}$} & \multicolumn{2}{|c|}{$\begin{array}{c}\text { Governamental } \\
\text { Abstrato }\end{array}$} & \multicolumn{2}{|c|}{$\begin{array}{c}\text { Governamental } \\
\text { Concreto }\end{array}$} \\
\hline & \multicolumn{2}{|c|}{$\beta$} & \multicolumn{2}{|c|}{$\beta$} & \multicolumn{2}{|c|}{$\beta$} & \multicolumn{2}{|c|}{$\beta$} \\
\hline & Art. $1^{\circ}$ & Art. 29 & Art. $1^{\circ}$ & Art. 29 & Art. $1^{\circ}$ & Art. 29 & Art. $1^{\circ}$ & Art. 29 \\
\hline \multicolumn{9}{|l|}{ Sócio-Demográficas } \\
\hline Idade & 0,20 & 0,14 & $-0,12$ & 0,01 & - & - & $-0,23^{*}$ & $-0,11$ \\
\hline Sexo & $-0,11$ & $-0,18$ & 0,02 & 0,01 & - & - & 0,08 & 0,12 \\
\hline Tempo de universidade & 0,17 & $-0,30^{*}$ & $-0,33$ & $-0,02$ & - & - & $-0,09$ & $-0,08$ \\
\hline \multicolumn{9}{|l|}{ Simpatia partidária } \\
\hline Esquerda & $0,36^{*}$ & $-0,01$ & 0,08 & $-0,12$ & - & - & $-0,17$ & 0,11 \\
\hline Direita & $-0,17$ & 0,01 & $-0,29 *$ & $-0,32 *$ & - & - & $0,27^{* *}$ & 0,04 \\
\hline \multicolumn{9}{|l|}{ Participação em: } \\
\hline Abaixo-assinados & 0,14 & 0,14 & $-0,10$ & 0,11 & - & - & $-0,01$ & 0,07 \\
\hline Eleições & $-0,10$ & 0,18 & $-0,05$ & 0,06 & - & - & $-0,54 * * *$ & $-0,15$ \\
\hline Manifestações & 0,16 & 0,07 & $-0,04$ & $-0,26^{*}$ & - & - & $-0,23^{*}$ & $-0,40 * * *$ \\
\hline Comitês & 0,16 & $-0,10$ & 0,13 & 0,06 & - & - & $-0,05$ & $-0,13$ \\
\hline Org. de DH & 0,14 & $0,36^{*}$ & $-0,02$ & $-0,12$ & _ & _ & $-0,06$ & 0,01 \\
\hline Coeficiente $R$ & $0,36^{*}$ & $0,40 * *$ & $0,49 * *$ & $0,32 * *$ & - & - & $0,70 * * *$ & $0,40 * *$ \\
\hline Coeficiente $R^{2}$ & 0,13 & 0,16 & 0,24 & 0,10 & _ & - & 0,49 & 0,16 \\
\hline
\end{tabular}

Nota: A idade dos estudantes varia de 18 a 44 anos. Na variável sexo, atribuíram -se os valores 1 para os homens e 2 para as mulheres. O tempo de universidade foi avaliado através do ano de ingresso dos estudantes no curso. A simpatia por partidos de esquerda e de direita são dummy variables, sendo 1 referente à simpatia e 0 à ausência de simpatia. A participação nas diversas atividades sócio -políticas foi computada com os valores 1 representando a não-participação e 2 a participação. Os travessões indicam a ausência completa de correlação significativa no princípio Governamental-abstrato. ${ }^{*} p<0,05$. ${ }^{* *} p<0,01 . \quad * * * p<0,001$.

dade ("todo homem tem deveres para com a comunidade, na qual o livre e pleno desenvolvimento de sua responsabilidade é possível”) - foram superiores aos seus envolvimentos pessoal e governamental em termos concretos. Ou seja, os respondentes julgam que devem fazer mais do que realmente fazem pelos DH. Estes resultados confirmam os obtidos por Doise, Dell'Ambrogio e Spini (1991) e Spini e Doise (1998) e apóiam a suposição desses autores de que, nas questões referentes ao que deveria ser feito, os indivíduos procuram responder de acordo com o que é esperado socialmente; porém, nas questões referentes às ações concretas, suas respostas aproximam-se de suas posições reais.

Já a constatação de que, em geral, o envolvimento pessoal é superior ao envolvimento governamental, contraria os resultados obtidos por Spini e Doise (1998). Entretanto, ao analisar mais detalhadamente a superioridade do envolvimento pessoal sobre o governamental, nos resultados apresentados neste trabalho, verifica-se que ela ocorre apenas em termos reais; no que deveria ser, a expectativa ou é a de que o governo faça mais do que o próprio indivíduo (Artigo 29), ou de que faça tanto quanto o próprio indivíduo (Artigo $1^{0}$ ). Note-se que, no Artigo 29, o resultado é semelhante ao de Spini e Doise (1998), indicando que, tanto nos países estudados por esses autores, como no Brasil, os respondentes possuem uma visão tradicionalista do cumprimento desse direito - ao governo mais do que ao indivíduo compete fazer mais pela comunidade. Segundo Spini e Doise (1998), esta visão tradicionalista teria a ver com a Declaração de 1948, que atribui aos governos a responsabilidade no cumprimento dos DH. Só recentemente, em 1993, as Nações Unidas deixaram clara a necessidade da participação individual na aplicação dos diretos humanos.

A análise mais detalhada da atribuição feita pelos estudantes sobre a responsabilidade individual e governamental no cumprimento dos direitos deixa, portanto, claro que são os resultados na dimensão do concreto que conduzem a uma superioridade do envolvimento pessoal sobre o governamental, isto é, o governo aparece fazendo menos do que os 
indivíduos pelo cumprimento dos diretos descritos nos Artigos $1^{\circ}$ e 29 . Por que os respondentes brasileiros, diferentemente dos suíços, julgam que eles fazem mais do que o governo pelo cumprimento dos direitos? Não sendo porque eles considerem que fazem muito, pois os resultados mostram médias baixas aos dois artigos, acredita-se que seja porque eles se apresentem mais críticos em relação ao governo do que os estudantes suíços. Esta interpretação recebe apoio de dados obtidos por Doise, Spini e Clémence (1999), que verificaram que estudantes brasileiros têm uma imagem mais positiva das suas ações pessoais em favor dos DH do que das ações governamentais. Enfim, julga-se que uma análise desses resultados, levando em consideração o contexto político brasileiro, pode significar que os respondentes tiveram expectativas mais elevadas sobre o que deveria ser feito pelos governantes do que os governantes foram capazes de realizar.

Em relação à interação entre princípios organizativos e tipo de artigo, observa-se que os estudantes julgam que eles próprios deveriam fazer mais pelo cumprimento do direito fundamental do que pelo cumprimento do dever para com a sociedade e que de fato eles julgam fazer mais pelo primeiro do que pelo segundo. Observa-se, além disso, que a crítica ao governo é maior em relação ao Artigo $1^{0}$ do que em relação ao Artigo 29. Por que a priorização do direito fundamental? É possível que esta priorização tenha a ver com a própria história de luta pelos $\mathrm{DH}$, que, inicialmente, priorizou os direitos fundamentais e que só, posteriormente, considerou os direitos voltados para a relação entre o indivíduo e a sociedade.

No que se refere ao estudo da moral, este artigo apontou para o fato de que tanto as telenovelas quanto o programa Você Decide veiculam predominantemente valores morais voltados para a defesa de interesses pessoais, utilitários ou hedonistas, e valores morais ligados a interesses corporativistas. Não se constatou, portanto, a preocupação dos meios de comunicação de massa com a transmissão de valores morais voltados para o bem-estar de todos os membros da sociedade ou com a transmissão de princípios de justiça válidos para qualquer cidadão.

Numa cultura em que os meios de comunicação veiculam, nos programas de maior audiência, valores individuais e corporativistas, como se dá o compromisso dos indivíduos com os direitos humanos, compromisso que pressupõe valores sociais mais abstratos e desinteressados? Em relação a essa questão observou-se que, os alunos se percebem como mais comprometidos, em termos de atividades concretas, em relação ao conteúdo do primeiro Artigo da DUDH, ao mesmo tempo em que percebem o maior descompromisso do governo com o cumprimento desse mesmo Artigo. Esta maior sensibilidade dos estudantes para com os direitos individuais revela uma perspectiva mais centrada nos interesses pessoais do que nos interesses sociais. Esta constatação parece reforçar a idéia de que, de fato, os valores transmitidos pelos programas televisivos, mencionados neste trabalho, apresentam um paralelismo - em termos de priorização de valores pessoais em lugar de societais -, com valores adotados pelos estudantes ao priorizarem os direitos individuais da DUDH.
Como se julga que ocorre a similitude entre valores televisivos e valores pessoais? Poder-se-ia pensar que as pessoas introjetam os valores morais transmitidos pela TV. Se assim fosse, poder-se-ia supor que, caso a TV passasse a transmitir valores morais relacionados com o bem estar social de uma forma ampla e intensiva, o telespectador adquiriria uma maior consciência de princípios morais e uma preocupação com o bem estar coletivo, um maior sentimento do dever e um maior envolvimento concreto com os DH. Acredita-se, como Kohlberg (1984) e Apel (1994), que quanto mais ampla a visão do social, maior a adesão a princípios universais de justiça e maior a capacidade de engajamento em ações concretas.

Entretanto, vale salientar que, mesmo que a TV transmitisse, de forma predominante, valores morais voltados para o bem estar coletivo, não necessariamente, todas as pessoas introjetariam esses valores. De fato, as visões de mundo dos membros de uma sociedade não podem ser pensadas como um conjunto de crenças unanimemente compartilhadas por todos, mas sim como um conjunto de significados que organizam as diversas crenças e atitudes que existem sobre um tema (Spini \& Doise, 1998).

Assim, é importante verificar que outros fatores contribuem para que as pessoas se posicionem sobre os direitos humanos. Dentre estes fatores, considerou-se nesta pesquisa o tipo de participação sócio-política dos indivíduos. Os resultados a este respeito demonstram que, em relação ao Artigo $1^{0}$, a simpatia por partidos políticos de esquerda contribui favoravelmente para um envolvimento dos indivíduos, em termos abstratos, com os direitos humanos. Entretanto, este tipo de identificação partidária não é suficiente para um envolvimento em atividades concretas. Já a simpatia por partidos de direita aparece negativamente associada a um envolvimento concreto do indivíduo em atividades correspondentes aos conteúdos dos dois Artigos analisados. Este último resultado está de acordo com o obtido por Moghaddan e Vuksanovic (1990, citado por Spini \& Doise, 1998) e Spini e Doise (1998). Outra variável que se mostrou relacionada com o envolvimento do estudante com os $\mathrm{DH}$, seja no nível abstrato, seja no concreto, foi o número de anos que ele passa na universidade. Constatou-se que, quanto maior o tempo que o estudante passa na universidade, menos ele se considera comprometido com os DH.

Embora se pudesse esperar que a passagem pela universidade colaborasse com o desenvolvimento político dos estudantes, o que os levaria a um maior comprometimento com os DH, Da Costa, Torres, Burity e Camino (1994), estudando a socialização política em universitários paraibanos, constataram que o número de anos que o estudante passa na universidade não influencia positivamente os diversos índices de participação política, e que estes índices são influenciados pela qualidade da inserção do estudante na vida universitária. Assim, esses autores observaram que quanto mais os estudantes participam de atividades extracurriculares como extensão, pesquisa, movimento estudantil, maiores são seus índices de participação política. 
Quanto à influência da variável "votar mesmo que não seja obrigatório" no envolvimento do governo, verificou-se que o fato do estudante desejar votar sempre se relaciona positivamente com a sua percepção de que o governo não se empenha suficientemente na aplicação do conteúdo do direito à liberdade-igualdade.

Estes resultados confirmam a suposição de Spini e Doise (1998) de que a participação ativa das pessoas em atividades sócio-políticas e reivindicatórias relacionar-se-ia com o envolvimento pessoal e com o desenvolvimento de uma visão crítica em relação aos governos, no que concerne à aplicação dos direitos humanos. Entretanto, não confirmam a suposição, desses autores, de uma relação entre a participação ativa em atividades reivindicatórias e o empenho concreto dos estudantes na aplicação dos conteúdos dos dois direitos analisados.

É importante destacar que, no conjunto das análises, há diferenças nos resultados relativos aos direitos, referentes aos Artigos $1^{0}$ e 29 , tanto na análise relativa ao nível de envolvimento dos indivíduos nesses direitos, como na análise da influência de variáveis psicossociais na percepção do envolvimento pessoal e governamental. Essas diferenças indicam que os indivíduos se identificam mais, ou são mais sensíveis ao conteúdo do Artigo $1^{\underline{0}}$, do que ao relativo ao Artigo 29. Observou-se que esses resultados corroboram os obtidos por Doise e Herrera (1994), que verificaram que os indivíduos privilegiam mais os direitos relativos aos princípios fundamentais (Artigos $1^{0}$ e $2^{\underline{0}}$ ) do que aqueles relativos à esfera coletiva e institucional (Artigos 28 a 29). Segundo esses autores, a divergência na consideração dessas classes de direitos estaria relacionada com diferentes graus de exposição dos indivíduos às informações sobre esses direitos: os princípios fundamentais seriam mais divulgados do que os da esfera coletiva. Esta suposição dos autores encontra respaldo nos achados de uma pesquisa de Clémence, Doise, De Rosa e Gonzalez (1995) em que foram encontradas diferenças no grau em que os indivíduos privilegiam uma ou outra classe de direitos em consonância com o tipo de sociedade individualista ou coletivista - em que vivem.

De acordo com os resultados obtidos, constata-se, como era esperado, que a participação política dos estudantes é decisiva para a forma como representam o comprometimento do governo e o pessoal com os $\mathrm{DH}$.

Constata-se, também, que os estudantes têm uma representação do governo brasileiro como não-defensor dos DH. Aliás, esta é uma representação corrente dos cidadãos dos países da América Latina, e constitui a base de diferenças entre esses países e os europeus. Entretanto, esta representação não é fato que teve origem na América Latina, ela faz parte de uma representação internacional.

$\mathrm{Na}$ verdade, tem-se criado a idéia de que os governantes dos países do $1^{0}$ Mundo respeitam mais os $\mathrm{DH}$ do que os governantes dos demais países, quando, na realidade, boa parte das transgressões aos direitos humanos dos cidadãos do $3^{\underline{0}}$ Mundo, por exemplo, vem de práticas econô- micas impostas pelas instituições e países do $1^{\underline{0}}$ Mundo, sem que isso afete a visão de seus habitantes.

Diante desta distorção na representação, resta aprofundar o estudo sobre possíveis fatores limitantes à percepção, nos países de $1^{\underline{0}}$ Mundo, de que seus próprios governantes colaboram com a prática de transgressão aos DH nos demais países, sobretudo nos do $3^{0}$ Mundo.

Além disso, é preciso compreender melhor a relação entre moral da sociedade e o respeito aos $\mathrm{DH}$, uma vez que os dados encontrados nesta pesquisa revelam um paralelismo entre os valores morais transmitidos por determinados programas de televisão e o tipo de Artigo da DUDH que foi mais valorizado pelos estudantes.

\section{Referências}

Apel, K. (1994). Estudos de moral moderna. Petrópolis: Vozes.

Camino, C. P. S., \& Cavalcanti, M. G. (1998). Valores morais transmitidos por telenovelas brasileiras: Vale Tudo, Tieta e Salvador da Pátria. In M. T. Nunes (Org.), Moral and TV (pp. 32-51). Porto Alegre: Evangraf.

Camino L., Silva, E. A., \& Souza, S. M. (1998). Primeiros passos para a elaboração de um modelo psicossociológico do comportamento eleitoral: estudo dos eleitores de João Pessoa na campanha de 1992. Estudos de Psicologia, 3, 7-32.

Camino, L., Torres, A. R., \& Da Costa, J. B. (1995). Voto, identificación partidária, identidad social y construcción de la ciudadania. In O. D’Adamo, V. G. Beaudoux, \& M. Montero (Orgs.), Psicologia de la acción política (pp. 129-142). Buenos Aires: Paidós.

Clémence, A., Doise, W., De Rosa, A. S., \& Gonzalez, L. (1995). La représentation sociale des droits de l'homme: une recherche internationale sur l'étendue et les limites de l'universalité. International Journal of Psychology, 30, 181212.

Da Costa, J., Torres, A. R. R., Burity, M. H., \& Camino, L. (1994). Universidade: espaço institucional para o desenvolvimento político. Temas, I, 17-36.

Dâmaso K. H. (1995). Julgamento moral e a televisão em Você Decide. Dissertação de mestrado não-publicada. Pontifícia Universidade Católica do Rio Grande do Sul, Porto Alegre.

Diaz-Veizades, J., Widaman, K. F., Little, T. D., \& Gibbs, K. W. (1995). The measurement and structure of Human Rights attitudes. Journal of Social Psychology, 135, 313-328.

Doise, W. (1976). L'articulation psychosociologique et les relations entre groupes. Bruxelas: De Boeck.

Doise, W. (1982). L'explication en psychologie sociale. Paris: Presses Universitaires de France.

Doise, W. (1998). Social psychology and human rights. European Review, 6, 349-355.

Doise, W., Dell'Ambrogio, P., \& Spini, D. (1991). Psychologie sociale et Droits de l'Homme. Revue Internationale de Psychologie Sociale, 4, 257277.

Doise, W., \& Herrera, M. (1994). Déclaration universelle et représentations sociales des droits de l'homme: une étude à Genève. Revue Internationale de Psychologie Sociale, 2, 87-107.

Doise, W., Staerklé, C., Clémence, A., \& Savory, F. (1998). Human rights and Genevan youth: a study of social representations. Swiss Journal of Psychology, 57, 86-100.

Doise, W., Spini, D., \& Clémence, A. (1999). Human rights studied as social representations in a cross-national context. European Journal of Social Psychology, 29, 1-29. 
Kelner, D. (2001). A cultura da mídia. Baurú: EDUC.

Kohlberg, L. (1976). Moral stages and moralization: the cognitive developmental approach. In T. Lickona (Org.), Moral development and behavior: theory, research and social issues (pp. 112-138). Nova York: Holt, Rinehart \& Winston.

Kohlberg, L. (1984). Essays on moral development: The psychology of moral development. Nova York: Harper \& Row.

Mello, J. M. (1988). Telemania, anestésico social. São Paulo: Edições Loyola.
Mendoza, R., \& Camino, L. (2000). Configuración del espacio político, el caso de los estudiantes brasileños. Revista Española de Psicología Política, 21, 7-29. Sampaio, I. S. V. (2000). Televisão, publicidade e infância. São Paulo: Annablume. Spini, D., \& Doise, W. (1998). Organizing principles of involvement in human rights and their social anchoring in values priorities. European Journal of Social Psychology, 28, 603-622.

United Nations (1993, June). World conference on human rights: the Vienna declaration and programme of action. Nova York: Autor.

\section{Notas}

1 Este artigo é fruto de pesquisa com apoio do CNPq

2 Na verdade, Kohlberg apresentou três tipos de moral: pré-convencional, convencional e pós-convencional. Consideram-se, aqui, as morais pré-convencional e convencional como heterônomas e a pós-convencional como autônoma.

3 África do Sul, Albânia, Alemanha, Argentina, Austrália, Áustria, Bélgica, Brasil, Bulgária, Camarões, Canadá, Costa do Marfim, Espanha, Estados Unidos, Equador, Filipinas, Finlândia, Grécia, Holanda, Índia, Indonésia, Irlanda do Norte, Itália, Iugoslávia, Japão, México, Portugal, República Tcheca, Reino Unido, Romênia, Rússia, Suíça, Tunísia, Zaire, Zimbábue.

Cleonice Camino, doutora em Psicologia Social pela Universidade Católica de Louvain (Bélgica), é coordenadora do Núcleo de Pesquisa em Desenvolvimento Sócio-Moral da Universidade Federal da Paraíba e professora visitante do Departamento de Psicologia da Universidade Federal de Pernambuco. Endereço para correspondência: Núcleo de Pesquisa em Desenvolvimento Sócio-Moral da Universidade Federal da Paraíba; Caixa Postal 5069; Cidade Universitária; João Pessoa, PB; CEP 58051-970. E-mail: cleocamino@yahoo.com.br Leoncio Camino, doutor em Psicologia Social pela Universidade Católica de Louvain (Bélgica), é professor no Departamento de Psicologia e coordenador do Grupo de Pesquisa em Comportamento Político da Universidade Federal da Paraíba e membro da Comissão Nacional de Direitos Humanos do Conselho Federal de Psicologia.

Cícero Pereira, mestre em Psicologia Social pela Universidade Federal da Paraíba, é professor de Psicologia Social na Universidade Católica de Goiás.

Márcia Paz, mestre em Psicologia Social pela Universidade Federal da Paraíba, é professora no Departamento de Psicologia e membro do Núcleo de Pesquisa em Desenvolvimento Sócio-Moral da Universidade Federal da Paraíba. 